\section{PENGARUH STRATEGI BISNIS \\ PERUSAHAAN DAN KOMPETISI \\ PASAR EKUITAS TERHADAP RISIKO \\ $C R A S H$ HARGA SAHAM DENGAN \\ OVERVALUED EQUITIES \\ SEBAGAI VARIABEL MEDIASI}

\author{
Fidya Gumilang Arianwuri, Sutrisno T, \\ Yeney Widya Prihatiningtias \\ Program Pasca Sarjana Universitas Brawijaya Malang \\ Jalan Veteran, Malang, Jawa Timur 65145, Indonesia. \\ Email: gumilangarianwuri@gmail.com
}

JRAK

\title{
Abstract
}

\begin{abstract}
Business Strategy, Equity Market Competition, Overvalued Equities, and Stock Price Crash Risk. The purpose of this research is to examine the influence of prospector business strategy and defender business strategy, equity market competition, and indirect effect of prospector business strategy on stock price crash risk through ovevalued equities. The sample of this research are 192 companies that are divided into 96 prospector business strategy and 96 defender business strategy during 2010-2016. This study uses a secondary data from financial report, number of investor, and stock price information. Which is obtained from the official website of IDX, KSEI and yahoo finance. The results of this study indicate that the prospector business strategy effect on the stock price crash risk, while the defender business strategy does not affect on stock price crash risk. The equity market competition is proven to reduce the stock price crash risk. The existence of a prospector business strategy will tend to overvalued equities which in turn, increase stock price crash risk.
\end{abstract}

Keywords: defender business strategy, equity market competition, overvalued equities, prospector business strategy, stock price crash risk

\section{PENDAHULUAN}

Pada hakikatnya, investor pasar modal tidak mengamati kecenderungan terjadinya crash harga saham, melainkan mengamati harga saham yang tercipta di pasar modal. Hal ini memiliki kelemahan karena harga harga saham tidak sepenuhnya merefleksikan kinerja perusahaan yang sesungguhnya. Adanya harga saham yang relatif tinggi, secara signifikan dapat menurun dengan sangat cepat. Hal ini dapat dikarenakan adanya beberapa usaha manajemen dalam menunda menginformasikan berita buruk yang pada akhirnya dapat menyebabkan risiko crash harga saham.

Risiko crash harga saham merupakan isu penting dalam melakukan analisis portofolio dan penentuan harga (asset pricing) (Li, Steven, Sue, 2016). Risiko crash harga saham merupakan suatu kondisi dimana harga saham menurun tajam dalam waktu yang relatif singkat (Aman, 2013). Jin dan Myers (2006) berpendapat bahwa risiko crash didasarka pada gagasan bahwa manajer memiliki kecenderungan untuk menahan berita buruk dalam beberapa waktu, yang memungkinkan berita buruk tersebut tidak diinformasikan kepada para investor. Ketika akumulasi berita buruk tersebut terakumulasi melewati ambang batas, manajer akan mengungkapkan informasi tersebut kepada pasar sekaligus, yang dapat menyebabkan penurunan yang signifikan pada harga saham.

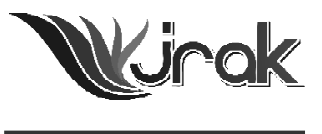

Jurnal Reviu Akuntansi dan Keuangan ISSN: 2088-0685 Vol. 7 No. 1, April 2017 Pp 963-976 


\section{Pengaruh Strategi Bisnis...}

Terdapat beberapa penelitian yang menunjukkan bahwa adanya risiko crash dapat terjadi karena beberapa faktor diantaranya yaitu; penelitian yang dilakukan oleh Hutton, Marcus, dan Tehranian (2009) dalam penelitiannya menyebutkan bahwa tindakan manajemen laba yang dilakukan perusahaan bertujuan untuk menutupi informasi yang buruk terhadap investor sampai titik tertentu, sehingga dapat menyebabkan risiko crash spesifik harga saham. Kim, Li, dan Zhang (2011a) menemukan bahwa adanya penghindaran pajak dapat memengaruhi risiko crash harga saham. Kim, Li, dan Zhang (2011b) menunjukkan bahwa insentif ekuitas antara CFO dan CEO dapat memengaruhi risiko crash harga saham. Dari penjelasan di atas dapat disimpulkan bahwa adanya tindakan manajemen laba, tindakan penghindaran pajak, serta adanya insentif ekuitas, strategi bisnis juga berpotensi sebagai salah satu faktor yang dapat memengaruhi risiko crash harga saham. Sebagai contoh, perusahaan yang mempertahankan ekspektasi kinerja masa depan investor yang terlalu optimistik, akan menerapkan strategu binsis yang agresif ketika perusahaan tersebut terlibat dalam manipulasi laba.

Penelitian terbaru yang dilakukan Bentley, Omer, Sharp (2013); Higgins, Omer, Phillips, (2015) menunjukkan bahwa adanya strategi bisnis yang dilakukan perusahaan agar tetap stabil dari waktu ke waktu dengan menunda berita buruk sampai batas tertentu. Dari sini dapat disimpulkan bahwa strategi bisnis perusahaan memiliki potensi untuk memiliki dampak urutan pertama pada risiko crash dan menyebabkan terjadinya konsekuensi ekonomi secara langsung bagi investor. Persaingan bisnis yang semakin tajam membuat setiap perusahaan harus mempunyai strategi bisnis dalam mengembangkan kegiatan usahanya. Strategii yang digunakan oleh perusahaan pun harus cocok dengan karakter perusahaan dan kondisi lingkungannya agar mampu bertahan dalam persaingan bisnis yang ketat.

Miles, Snow, Meyer, dan Coleman (1978) menjelaskan bahwa terdapat empat strategi bisnis yang layak yang mungkin ada secara bersamaan diantaranya yaitu: strategi bisnis prospector, defender, reactor dan analyzers. Hal tersebut didasarkan pada perbedaan besarnya dan arah perubahan mengenai produk dan pasar (Hambrick, 1983). Tipologi prospector banyak melakukan perubahan dalam menjalankan perusahaannya. Tipologi defender menjalankan perusahaannya dengan stabil tanpa melakukan banyak perubahan. Tipologi reactor merupakan jenis perusahaan yang lebih banyak ditekan oleh lingkungan, karena kurang memperhatikan adanya perubahan lingkungan dan sistem persaingan. Tipologi analyzer memiliki pasar produk yang stabil dan melakukan perubahan-perubahan. Hal ini menunjukkan strategi bersaing prospector dan defender merupakan tipologi strategi yanng berada pada titik ekstrim yang berlawanan.

Perusahaan yang menerapkan strategi prospector memiliki tingkat ketidakpastian outcome yang lebih tinggi, yang dapat menyebabkan tingkat asimetri informasi (Habib dan Mostafa, 2017). Bentley, Newton, dan Thompson (2015) secara empiris menemukan bahwa manajer perusahaan dengan strategi prospector lebih cenderung untuk menunda berita buruk, karena (i) struktur kompensasi eksekutif (Rajagopalan, 1997); (ii) kecenderungan untuk menghinddari pajak yang lebih tinggi (Higgins et al, 2015); dan (iii) eksposur risiko litigasi. Hasil penelitian tersebut menjelaskan bahwa kecenderungan penundaan berita buruk terkait dengan strategi prospector membuatnya lebih rentan terhadap risiko crash.

Salah satu cara untuk mengurangi risiko crash harga saham yaitu adanya persaingan pasar ekuitas. Sejauh mana para manajer secara konsisten dapat menyembunyikan berita buruk, kemungkinan akan menurun dalam tingkat persaingan pasar ekuitas. Investor yang piawai dapat berusaha untuk mendapatkan informasi pribadi dengan memperoleh informasi (negatif) yang tidak diungkapkan oleh manajemen. Namun, biaya perdagangan yang tinggi dapat mengurangi insentif tersebut dengan mengurangi nilai sekarang dari perdagangan investor yang diinformasikan. Tingkat persaingan yang lebih tinggi menurunkan biaya perdagangan investor yang terinformasi, sehingga meningkatkan kemauan mereka untuk mendapatkan informasi dan perdagangan pribadi. Hal ini 
memungkinkan lebih banyak informasi untuk disimpan menjadi harga saham. Oleh karena itu, jika tingkat persaingan pasar ekuitas tinggi, kemungkinan berita buruk bisa menumpuk lebih rendah dan probabilitas penurunan harga saham diperkirakan akan lebih rendah pula.

Risiko crash harga saham juga dapat terjadi karena adanya overvalued equities. Secara konsep overvalued equities merupakan suatu keadaan yang mana harga saham suatu perusahaan melebihi nilai fundamentalnya (Jensen, 2005). Selain itu, Jensen (2005) berpendapat bahwa overvalued equities dapat menciptakan bentuk biaya agensi yang mengarahkan manajer untuk terlibat dalam kegiatan menghancurkan nilai. Tindakan tersebut dapat menjadi over investasi melalui akuisisi atau ekspansi, melakukan fraud, dan mengelola laba (Chi dan Gupta, 2009). Overvalued seperti itu sering disebabkan oleh antusiasme berlebihan namun tidak berkelanjutan dalam jangka panjang. Hal ini membuat perusahaan menjadi overvalued.

Penelitian ini merupakan pengembangan dari penelitian Habib dan Mostafa (2017) dan Vorst (2016). Penelitian ini dilakuan pada perusahaan manufaktur yang terdaftar di Bursa Efek Indonesia (BEI) tahun 2010 - 2016. Alasan pemilihan perusahaan manufaktur sebagai objek penelitian adalah karena perusahaan manufaktur termasuk ke dalam industri yang semakin berkembang dalam dunia bisnis saat ini dan memiliki kontribusi yang besar dalam perkembangan pasar modal. Perusahaan manufaktur merupakan kelompok industri yang sahamnya paling aktif diperdagangkan di Bursa Efek Indonesia, sehingga dapat mencerminkan reaksi pasar modal secara keseluruhan. Perusahaan manufaktur juga memiliki jumlah perusahaan terbanyak di BEI. Berdasarkan latar belakang penelitian yang telah dipaparkan sebelumnya, rumusan masalah dalam penelitian ini adalah sebagai berikut:

1. Apakah perusahaan dengan strategi bisnis prospector dan strategi bisnis defender berpengaruh terhadap risiko crash harga saham?

2. Apakah kompetisi pasar ekuitas berpengaruh terhadap risiko crash harga saham?

3. Apakah strategi bisnis prospector berpengaruh terhadap risiko crash harga saham melalui overvalued equity?

\section{Landasan Teori}

\section{The Bad News Hoarding Theory}

The bad news hoarding theory berasal dari kenyataan bahwa manajer memiliki berbagai motivasi strategis untuk menyembunyikan dan menumpuk berita buruk dalam perusahaan. Jin dan Myers (2006) menemukan bukti secara konsisten terkait dengan sifat masalah agensi yang memotivasi manajer untuk mengontrol strategi pengungkapan berita buruk tentang perusahaan kepada publik. Jind dan Myers (2006) menemukan bahwa motif keuangan merupakan alasan penting bagi manajer untuk mengumpulkan berita buruk dalam perusahaan. Ball (2009) menunjukkan bahwa motivasi nonfinansial, seperti menjaga kinerja perusahaan sangat kuat sehingga menjadi alasan utama untuk menyembunyikan informasi negatif. Secara kolektif, penelitian Jin dan Myers (2006) dan Ball (2009) menemukan bahwa kedua motif finansial dan nonfinansial memainkan peran penting bagi manajer untuk memungkinkan menahan berita buruk dalam perusahaan.

\section{Agency Cost of Overvalued Equity}

Jensen (2005) secara konsep menyebutkan bahwa overvaluation equities merupakan suatu keadaan dimana harga saham suatu perusahaan melebihi nilai fundamentalnya. Overvalued seperti itu sering disebabkan oleh antusiasme yang berlebihan yang tidak berkelanjutan dalam jangka panjang (Shiller, 2000). Hal ini membuat perusahaan menjadi lebih overvalued, tekanan untuk memenuhi 


\section{Pengaruh Strategi Bisnis...}

966 target pendapatan yang semakin realistis menjadi lebih besar sehingga memaksa manajer untuk terlibat dalam manipulasi laba untuk memenuhi atau mengalahkan ekspektasi pasar (Jensen, 2005). Biaya yang terkait dengan overvalued equities yang tinggi, pada akhirnya akan diketahui pasar, bahwa overvaluation perusahaan didukung oleh manajemen laba dan harga saham perusahaan menjadi merosot atau bahkan dapat menyebabkan crash (Jensen, 2005).

\section{Risiko Crash Harga Saham}

Risiko crash merupakan momen ketiga return saham yang menunjukkan skewness negatif, hal ini berbeda dari langkah-langkah lain yang diteliti dalam penelitian sebelumnya, seperti return rata-rata (momen pertama), dan varian dari retrurn saham (momen kedua) (Habib dan Mostafa, 2017). Menurut Aman (2013) risiko crash harga saham merupakan suatu kondisi ketika harga saham menurun tajam dalam waktu yang relatif singkat. Secara konseptual risiko crash didasarkan pada gagasan bahwa manajer memiliki kecenderungan untuk menahan berita buruk untuk beberapa waktu, sehingga berita buruk tersebut tidak diinformasikan kepada para investor. Ketika akumulasi berita buruk tersebut melebihi ambang batas, manajer akan mengungkapkan informasi tersebut kepada pasar sekaligus, yang dapat menyebabkan penurunan negatif yang besar pada harga saham (Jin dan Myers, 2006).

\section{Tipe Strategi Bisnis}

Salah satu penentu tingkat perusahaan dalam terjadinya risiko crash yaitu disebabkan oleh strategi bisnis yang diterapkan oleh individu perusahaan. Setiap perusahaan memiliki tipe strategi bisnis yang berbeda dalam menjalankan bisnisnya. Wheelen dan Hunger (2012) berpendapat pengertian tipe strategi, sebagai berikut:" a strategic type is a category of firms based on a common strategic orientation of structure, culture, and processes consistent with that strategy".

Miles, Snow, Meyer, dan Coleman (1978) mengklasifikasikan tippologi strategi yang layak yang mungkin ada secara bersamaan dalam suatu industri diantaranya yaitu, prospectors, defender, analyzer, dan reactor. Tipologi strategi prospector berfokus pada inovasi produk, peluang pasar, pengejaran pertumbuhan penjualan, dan menekankan persaingannya melalui penawaran produk yang unik (differentiation strategy). Tipologi strategi defender berfokus pada stabilitas pasar, dan menawarkan serta mencoba untuk melindungi lini produk yang terbatas untuk segmen yang sempit dari pasar yang potensial. Tipologi strategi analyzer mencoba mengambil yang terbaik dari kedua strategi sebelumnya. Tipologi strategi reactor secara sederhana bereaksi pada perubahan lingkungan dan secara karakteristik kurang koheren sehingga tidak dapat merespon secara cepat pada perubahan lingkungan.

\section{Kompetisi Pasar Ekuitas}

Salah satu cara untuk mengurangi risiko crash harga saham yaitu adanya kompetisi pasar ekuitas. Harga saham akan lebih informatif pada saat persaingan pasar ekuitas tinggi. Tingkat persaingan yang lebih tinggi menurunkan biaya perdagangan investor yang diinformasikan, sehingga meningkatkan kemauan mereka untuk mendapatkan informasi dan perdagangan pribadi. Tingkat persaingan yang lebih tinggi menurunkan biaya perdagangan investor yang diinformasikan, sehingga meningkatkan kemauan mereka untuk mendapatkan informasi dan perdagangan pribadi. Hal ini memungkinkan lebih banyak informasi untuk disita menjadi harga saham. Oleh karena itu, jika tingkat persaingan pasar ekuitas tinggi, kemungkinan berita buruk bisa menumpuk lebih rendah dan probabilitas penurunan harga saham diperkirakan akan lebih rendah juga (Vorst, 2016). Sejauh mana para manajer secara konsisten menyembunyikan berita buruk, kemungkinan akan menurun dalam tingkat kompetisi pasar ekuitas. Investor yang 
terinformasi dapat berusaha untuk mendapatkan informasi pribadi dengan memperoleh informasi (negatif) yang tidak diungkapkan oleh manajemen. Namun, biaya perdagangan yang tinggi dapat mengurangi insentif tersebut dengan mengurangi nilai sekarang dari perdagangan investor yang diinformasikan.

\section{Overvalued Equities}

Jensen (2005) menjelaskan bahwa overvaluation ekuitas terjadi ketika harga saham suatu perusahaan lebih tinggi dari nilai yang mendasarinya. Artinya, perusahaan tidak mampu memberikan kinerja keuangan yang dibutuhkan pasar untuk membenarkan penilaian itu. Menurut Jensen dan Meckling (1976), biaya agensi muncul ketika suatu entitas, prinsipal mempekerjakan agen. Mereka mendefinisikan biaya agensi sebagai jumlah dari kontrak, monitoring, dan biaya bonding yang dilakukan untuk mengurangi biaya akibat konflik kepentingan ditambah "kerugian residual" yang terjadi karena umumnya tidak mungkin secara sempurna menyelaraskan kepentingan para agen yang sama dengan kepentingan prinsipal. Jensen (2005) menekankan bahwa terdapat biaya agensi yang mahal terkait dengan overvalued equities. Overvalued equities sering disebabkan oleh antusiasme yang berlebihan yang tidak berkelanjutan dalam jangka panjang.

\section{Hipotesis Penelitian}

\section{Pengaruh Strategi Bisnis Prospector dan Strategi Bisnis Defender terhadap Risiko Crash Perusahaan}

The bad news hoarding theory menjelaskan bahwa manajer memiliki motivasi strategis untuk menyembunyikan dan menumpuk berita buruk dalam perusahaan. Habib dan Mostafa (2017) berpendapat bahwa penimbunan berita buruk menyebabkan risiko crash harga saham. Strategi bisnis prospectors cepat mengubah bauran produk pasar mereka untuk menjadi pemimpin pasar yang inovatif, sementara strategi bisnis defender berkonsentrasi pada basis produk yang sempit dan stabil untuk bersaing atas dasar harga, layanan, atau kualitas (Miles, Snow, Meyer, dan Coleman, 1978). Kecenderungan prospector untuk menahan berita buruk, dan probabilitas berikutnya yang lebih tinggi dari risiko crash, juga dapat didasarkan pada pengamatan bahwa prospector menderita tingkat asimetri informasi yang lebih tinggi dibandingkan dengan rekan-rekan defender (Kothari et al., 2009). Dapat disimpulkan bahwa prospectors lebih mungkin untuk mengalami risiko crash di masa depan. Berdasarkan penjelasan di atas penelitian ini mengembangkan hipotesis sebagai berikut:

$\mathrm{H} 1 \mathrm{a} \quad$ : Strategi bisnis perusahaan prospector berpengaruh terhadap risiko crash harga saham.

$\mathrm{H} 1 \mathrm{~b} \quad$ : Strategi bisnis perusahaan defender berpengaruh terhadap risiko $c r a s h$ harga saham

\section{Pengaruh Kompetisi Pasar Ekuitas terhadap Risiko Crash Harga Saham}

Jika investor adalah price taker, jika perdagangan investor tidak mempengaruhi harga saham, pasar dikatakan kompetitif sempurna. Jika jumlah investor meningkat, dampak harga dari perdagangan investor yang diinformasikan akan menurun, sehingga mengurangi biaya perdagangan dan meningkatkan kesediaan mereka untuk memperoleh dan memperdagangkan informasi pribadi. Akibatnya, kemampuan manajer untuk menumpuk berita buruk secara signifikan berkurang di pasar ekuitas yang kompetitif, yang seharusnya memanifestasikan dirinya dalam probabilitas penurunan harga saham yang lebih rendah. Sehingga hipotesis penelitian ini sebagai berikut:

$\mathrm{H}_{2}$ : Kompetisi pasar ekuitas berpengaruh terhadap risiko crash saham. 


\section{Pengaruh Strategi Bisnis...}

\section{Pengaruh Strategi Bisnis Prospector terhadap Risiko Crash Harga Saham melalui Overvalued Equities}

Jensen (2005) menyatakan bahwa teori overvalued dapat disebabkan oleh jenis biaya agensi baru yaitu biaya agensi overvalued equities. Overvalued dapat menciptakan kerugian kesejahteraan yang besar dengan mengurangi kepercayaan investor terhadap integritas pasar modal dan mendorong tindakan manipulasi biaya yang harus dilakukan oleh regulator. Ekuitas yang terlalu rendah juga cenderung menghasilkan hasil yang tidak efisien untuk kontrak berdasarkan harga saham (Beneish dan Nichols, 2009). Habib dan Mostafa (2017) berpendapat bahwa strategi bisnis prospectors akan cenderung terhadap overvalued equity karena terdapat bukti yang menunjukkan bahwa investor memiliki ekspektasi optimis tentang prospek pertumbuhan saham (Lakonishok et al., 1994; Skinner dan Sloan, 2002). Strategi bisnis prospector dinilai lebih overvalued, sehingga perusahaan - perusahaan ini akan memliki insentif untuk menahan berita buruk untuk mempertahankan overvalued tersebut. Berdasarkan argumen di atas penelitian ini mengembangkan hipotesis sebagai berikut:

$\mathrm{H}_{3}$ : Strategi bisnis perusahaan prospector berpengaruh terhadap risiko crash harga saham melalui overvalued equities.

\section{METODE PENELITIAN}

Penelitian ini termasuk dalam jenis penelitian korelasional. Penelitian ini menggunakan variabel independen berupa strategi bisnis perusahaan yang terdiri strategi bisnis perusahaan prospector dan strategi bisnis perusahaan defender, serta kompetisi pasar ekuitas. Variabel dependen yang diuji adalah risiko crash harga saham, selain itu terdapat variabel mediasi dalam pengaruh strategi bisnis prospector terhadap risiko crash harga saham, yaitu overvalued equities.

Populasi dalam penelitian ini merupakan perusahaan manufaktur yang terdaftar di Bursa Efek Indonesia tahun 2010 - 2016. Pemilihan pengambilan sampel yang dipilih dalam penelitian ini yaitu judgement sampling. Penelitian ini menggunakan jenis data sekunder yang bersifat kuantitatif berupa laporan tahunan (annual report) dan data harga saham tahun 2010 - 2016. Laporan tahunan (annual report) digunakan untuk memperoleh variabel - variabel peneliti terkait dengan, risiko crash harga saham, strategi bisnis, kompetisi pasar ekuitas, dan overvalued equities. Data sekunder dikumpulkan dari berbagai sumber dari website resmi BEI, KSEEI, dan Yahoo Finance.

Risiko crash harga saham merupakan risiko penurunan tajam harga saham dalam rentang yang signifikan setelah harga sempat melambung tinggi (Kim dan Zhang: 2012). Variabel ini diukur menggunakan model yang dikembangkan oleh Chen et al. (1999) dengan rumus sebagai berikut:

$$
\operatorname{NCSKEW}_{\mathrm{it}+1}=\frac{-\left(\mathrm{n}(\mathrm{n}-1)^{3 / 2} \Sigma \mathrm{W}_{\mathrm{it}+1}\right)^{3}}{(\mathrm{n}-1)(\mathrm{n}-2)\left(\Sigma \mathrm{W}_{\mathrm{it}+1}\right)^{3 / 2}}
$$

Strategi bisnis perusahaan (STRATEGI) merupakan strategi yang digunakan perusahaan agar mampu beradaptasi menghadapi lingkungan yang kompetitif. Pengukuran strategi bisnis ini didasarkan pada penelitian Habbe dan Hartono (2001) yang diambil dari penelitian Skinner (1993) serta Kallapur dan Trombley (1999). Variabel indikator dari proksi perusahaan prospector dan defender dirumuskan sebagai berikut:

$\begin{array}{ll}\text { KARPEN } & =\text { KAR/PENJ } \\ \text { PBV } & =\mathrm{MV} / \mathrm{BV} \\ \mathrm{CETA} & =(\mathrm{CEt}-\text { Cet }-1) / \mathrm{TAt}-1 \\ \text { CEMVA } & =(\text { CEt }- \text { Cet }-1) / \mathrm{MVEt}^{-}-1\end{array}$


Penelitian Habbe dan Hartono (2001) menyatakan bahwa Principal Component Analysis terdiri dari tiga nilai, yaitu: communalities dari empat variabel indikator, eigenvalues untuk pengurangan matriks korelasi, dan korelasi antara faktor dengan empat indikator. Besarnya nilai communalities kemudian dijumlah dan harus mempunyai hasil yang sama dengan penjumlahan nilai (factor $1+$ factor2) dari nilai eigenvalues. Faktor1 dan Faktor2 merupakan indikator variabel representasi dari variabel KARPEN, PBV, CEMVE, dan CETA setelah diekstrasi dengan principal component analysis. Sedangkan Fac_sum adalah variabel penjumlahan dari skor Faktor 1 dan Faktor2 yang merupakan indeks untuk mengklasifikasi perusahaan bertipologi prospector atau bertipologi defender. Perusahaan bertipologi prospector dan defender ditentukan berdasarkan pada penjumlahan indeks kedua (factor1 + factor2). Penjumlahan indeks ini (fac_sum) kemudian diperingkat.

Pasar persaingan ekuitas dihitung dengan logaritma natural dari jumlah investor dalam suatu perusahaan. Pengukuran ini mengacu pada penelitian Vorst (2016) dan Amstrong (2011). Penelitian ini menggunakan dua pengukuran yang digunakan dalam menentukan overvalued equities diantaranya yaitu dengan PE (Price to Earning) dan PB (Price to Book). Hal ini didasarkan pada penelitian Habib dan Rong (2013). Pemilihan pengukuran tersebut dipilih karena dapat membantu dalam segi pihak perusahaan dan pihak investor dalam mendeteksi kondisi ekuitas perusahaan mengalami overvalued atau tidak.

Analisis data yang digunakan dalam penelitian ini menggunakan analisis jalur (path analysis) dengan aplikasi SPSS Ver 20.0. Analisis data dalam penelitian ini meliputi statistik deskriptif, pengujian asumsi klasik yang terdiri dari uji normalitas, uji heteroskedastisitas, uji multikolinearitas, dan uji autokorelasi serta pengujian hipotesis.

\section{HASIL DAN PEMBAHASAN}

Berdasarkan 854 jumlah observasi perusahaan yang masuk ke dalam sektor manufaktur selama tahun 2010 - 2016, data yang menjadi sampel penelitian adalah sebanyak 224 perusahaan.

\begin{tabular}{clc}
\hline No & \multicolumn{1}{c}{ Kriteria Pengambilan Sampel } & Jumlah \\
\hline 1 & Perusahaan manufaktur yang terdaftar di Bursa Efek Indonesia & 854 \\
& tahun 2010 - 2016. & $(210)$ \\
2 & Jumlah saham dengan akumulasi kerugian pada ekuitas. & $(189)$ \\
3 & Laporan perusahaan dengan mata uang dollar & $(98)$ \\
4 & Perusahaan yang tidak memiliki 26 kali return mingguan yang & \\
& positif & $(133)$ \\
5 & Laporan keuangan yang tidak teraudit & 224 \\
& Jumlah sampel dalam penelitian & $(32)$ \\
6 & Perhitungan t+1 untuk skewness negative & 192 \\
\hline
\end{tabular}

Tabel 1

Pengambilan Sampel Penelitian

Sumber: hasil olahan peneliti, 2017

\section{Seleksi Perusahaan Bertipologi Prospector dan Defender}

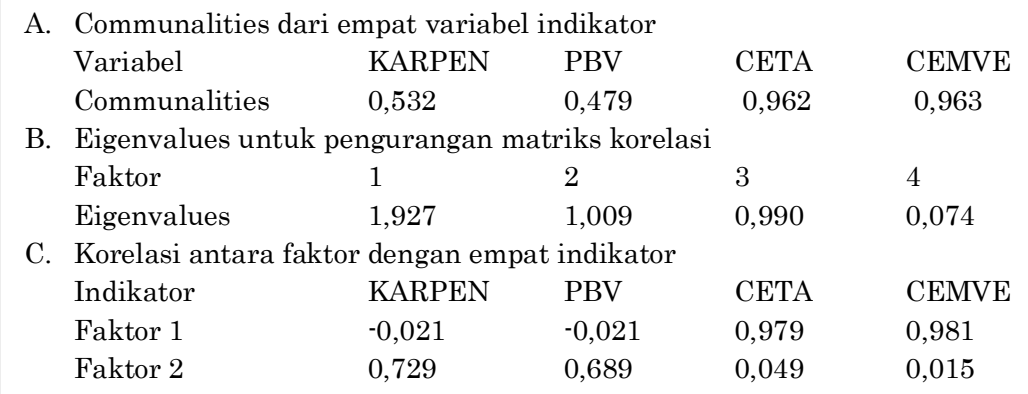




\section{Pengaruh Strategi Bisnis...}

Tabel 2 menunjukkan hasil principal component analysis terhadap empat indikator atau proksi strategi organisasional. Pada tabel $2 \mathrm{~A}$ dapat dilihat bahwa nilai communalities indikator dari strategi organisasional. Communalities digunakan untuk menentukan jumlah faktor representasi atau variabel - variabel asli yang terbagi dengan semua variabel yang termasuk dalam analisis. Jumlah keempat nilai communalities tersebut adalah sebesar 2,936. Untuk mencapai nilai tersebut dibutuhkan hanya dua faktor saja yang mempunyai nilai eigenvalues diatas satu, yaitu satu 1,927 dan faktor dua 1,009. Hal ini sejalan dengan the rule of thumb bahwa jumlah faktor yang mempunyai nilai eigenvalues sama dengan atau lebih dari satu (Habbe dan Hartono, 2001).

Berdasarkan analisis faktor yang dilakukan, diperoleh masing - masing 96 perusahaan menerapkan strategi prospector, dan 96 perusahaan menerakan strategi defender dari 192 perusahaan yang terpilih sebagai sampel penelitian.

\section{Statistik Deskriptif}

\begin{tabular}{lccccc}
\hline \multicolumn{1}{c}{ Variabel } & $\mathbf{N}$ & Minimum & Maksimum & Mean & Deviasi Standar \\
\hline CRASH & 192 & $-0,76$ & 0,98 & $-0,0005$ & 0,25325 \\
(NCSKEW) & & & & & \\
STRATEGI & 192 & $-1,46$ & 14,04 & 0,0561 & 1,51038 \\
EMCOMP & 192 & 2,53 & 2,62 & 2,554 & 0,03015 \\
PB & 192 & 0,12 & 62,93 & 5,2774 & 10,1292 \\
PE & 192 & 1,73 & 113 & 19,4281 & 14,4535 \\
\hline
\end{tabular}

Sumber: data diolah, 2017

Nilai rata - rata risiko crash harga saham dengan pengukuran nilai skewness negatif atau CRASH adalah sebesar -0,0005 dengan deviasi standar sebesar 0,25325. Nilai minimal risiko crash sebesar -0,76 dan nilai maksimal sebesar 0,98. Semakin tinggi nilai skewness negatif yang dihasilkan, semakin tinggi pula kecenderungan suatu perusahaan mengalami risiko crash harga saham.

Strategi bisnis diukur dengan analisis faktor menunjukkan nilai rata-rata sebesar 0,0561 dengan nilai deviasi standar 1,510. Nilai minimal dan maksimal strategi bisnis masing - masing sebesar -1,46 dan 14,04. Nilai deviasi standar yang lebih tinggi dibandingkan dengan nilai rata - rata mengindikasikan bahwa terdapat variasi yang besar antara nilai minimal dan maksimal selama periode pengamatan atau dapat dikatakan bahwa terdapat kesenjangan yang besar dalam variabel strategi bisnis perusahaan.

Persaingan pasar ekuitas (EMCOMP) yang diukur dengan logaritma natural jumlah investor yang terdapat dalam Bursa Efek Indonesia, menunjukkan nilai rata - rata sebesar 2,556 dengan nilai deviasi standar 0,030. Nilai minimal persaingan pasar ekuitas sebesar 2,53 dan nilai maksimal sebesar 2,62. Semakin tinggi nilai persaingan pasar ekuitas yang dihasilkan, semakin tinggi pula persaingan investor dalam pasar modal.

Variabel overvalued equity yang diukur dengan dua pengukuran yaitu PB (price to book) dan PE (price to earning). Pengukuran overvalued equity dengan menggunakan PBV menunjukkan rata - rata sebesar 5,277 dengan nilai deviasi standar sebesar 10,129. Rata - rata tersebut menunjukkan bahwa harga per lembar saham perusahaan telah mencapai 5,277 kali dari ekuitas per lembar sahamnya. Rasio PB terendah adalah 0,12 dan rasio PB terbesar adalah 62,92. Nilai deviasi standar PBV yang lebih besar dibandingkan dengan nilai rata - rata mengindikasikan bahwa terdapat variasi yang besar antara nilai minimal dan maksimal selama periode pengamatan atau dapat dikatakan bahwa terdapat kesenjangan yang besar dalam variabel overvalued equity dengan pengukuran yang digunakan adalah PB. 
Variabel overvalued equity yang diukur dengan PE menunjukkan rata rata sebesar 19,428 dengan nilai deviasi standar sebesar 14,453. Rata - rata tersebut menunjukkan bahwa harga per lembar saham perusahaan telah mencapai 19,428 kali dari laba per lembar sahamnya. Rasio PB terendah adalah 1,73 dan rasio PB terbesar adalah 113,00. Nilai deviasi standar PE yang lebih kecil dibandingkan dengan nilai rata - rata mengindikasikan bahwa terdapat variasi yang kecil antara nilai minimal dan maksimal selama periode pengamatan atau dapat dikatakan bahwa tidak ada kesenjangan yang besar dalam variabel overvalued equity dengan pengukuran yang digunakan adalah PB.

\section{Pengujian Asumsi Klasik}

Pengujian asumsi klasik yang digunakan dalam penelitian ini ditujukan untuk mengetahui apakah model dalam persamaan regresi memenuhi syarat asumsi klasik yang diajukan. Pengujian asumsi klasik yang telah dilakukan dalam penelitian ini sebelum melakukan uji regresi yaitu meliputi uji normalitas, uji heteroskedastisitas, uji multikolinieritas, dan uji autokorelasi.

\section{Pengujian Hipotesis Pertama}

\begin{tabular}{ccccl}
\hline $\begin{array}{c}\text { Unstandardized } \\
\text { Coeffisient / B }\end{array}$ & $\mathbf{t}$ & Sig & $\mathbf{R}^{2}$ & \multicolumn{1}{c}{ Keterangan } \\
\hline 0,022 & 2,174 & 0,032 & 0,038 & $\mathrm{H}_{1 \mathrm{a}}$ diterima \\
$-0,028$ & $-0,52$ & 0,604 & $-0,008$ & $\mathrm{H}_{1 \mathrm{~b}}$ ditolak \\
\hline
\end{tabular}

Sumber: Data diolah, 2017

Hipotesis 1a menyatakan bahwa strategi prospector berpengaruh terhadap risiko crash harga saham. Berdasarkan pengujian tersebut diketahui bahwa variabel strategi prospector memiliki nilai signifikansi sebesar 0,032 $(<0,05)$ dengan koefisien regresi sebesar 0,022 dan nilai t sebesar 2,174. Dengan demikian hipotesis $\mathrm{H} 1 \mathrm{a}$ diterima.

Hipotesis $1 \mathrm{~b}$ menyatakan bahwa strategi defender berpengaruh terhadap risiko crash harga saham. Berdasarkan hasil pengujian diketahui bahwa variabel strategi defender memiliki nilai signifikansi sebesar 0,604 (>0,05) dengan koefisien regresi sebesar -0,028 dan nilai t sebesar -0,520. Dengan demikian hipotesis H1b ditolak. Hal ini menunjukkan bahwa strategi defender tidak berpengaruh terhadap risiko crash harga saham.

\section{Pengujian Hipotesis Kedua}

\begin{tabular}{ccccc}
\hline $\begin{array}{c}\text { Unstandardized } \\
\text { Coeffisient / B }\end{array}$ & $\mathbf{t}$ & Sig & $\mathbf{R}^{2}$ & Keterangan \\
\hline$-3,654$ & $-6,659$ & 0,000 & 0,185 & $\mathrm{H}_{2}$ diterima \\
\hline
\end{tabular}

Sumber: Data diolah, 2017

Hipotesis 2 menyatakan bahwa persaingan pasar ekuitas berpengaruh terhadap risiko crash harga saham. Berdasarkan hasil pengujian diketahui bahwa persaingan pasar ekuitas memiliki nilai signifikansi sebesar $0,000(<0,05)$ dengan koefisien regresi sebesar -3,654 dan nilai t sebesar -6,659. Dengan demikian hipotesis 2 diterima. 


\section{Pengaruh Strategi Bisnis...}

Pengujian Hipotesis Ketiga

\begin{tabular}{ccccc}
\hline $\begin{array}{c}\text { Unstandardized } \\
\text { Coeffisient / B }\end{array}$ & $\mathbf{t}$ & Sig & $\mathbf{R}^{2}$ & Keterangan \\
\hline 0,002 & 2,431 & 0,017 & 0,078 & $\mathrm{H}_{3}$ diterima (PB) \\
$-0,001$ & $-3,140$ & 0,002 & 0,078 & $\mathrm{H}_{3}$ diterima (PE) \\
\hline
\end{tabular}

Sumber: Data diolah, 2017

Pengujian hipotesis 3 menyatakan bahwa pengaruh strategi prospector terhadap risiko crash harga saham melalui overvalued equities dengan melihat signifikansi t dan koefisien pada model regresi atau persamaan 3. Pada model regresi 3, koefisien regresi dan nilai t variabel mediasi dengan menggunakan pengukuran PB masing - masing sebesar 0,002 dan 2,431 dengan signifikansi 0,017 $(<0,05)$. Hasil pengujian tersebut menunjukan bahwa strategi bisnis prospector berpengaruh terhadap risiko crash harga saham melalui PB sebagai pengukuran overvalued equity. Selain itu koefisien regresi dan nilai t variabel mediasi dengan menggunakan pengukuran PE masing - masing sebesar -0,001 dan -3,140 dengan signifikansi 0,002 $(<0,05)$. Hasil pengujian tersebut menunjukkan bahwa strategi bisnis prospector berpengaruh terhadap risiko crash harga saham melalui $\mathrm{PE} \mathrm{se}-$ bagai pengukuran overvalued equity.

\section{Pembahasan Hasil Penelitian}

Hipotesis satu (a) menyatakan bahwa strategi bisnis prospector berpengaruh terhadap risiko crash harga saham. Hasil pengujian ini menunjukkan bahwa hipotesis satu (a) diterima. Hasil penelitian ini mendukung penelitian terdahulu yang dilakukan oleh Habib dan Mostafa (2017), yang menunjukkan bahwa strategi prospector cenderung dapat menyebabkan risiko crash harga saham.

Adanya Strategi bisnis perusahaan merupakan salah satu faktor yang dapat menyebabkan terjadinya risiko crash harga saham. Berdasarkan penelitian Miles, Snow, Meyer, dan Coleman (1978) mengenai strategi bisnis perusahaan terdapat empat strategi bisnis perusahaan. Salah satunya fokus utama tipe strategi bisnis dalam penelitian Miles, Snow, Meyer, dan Coleman (1978) yaitu tentang strategi bisnis prospector dan defender. Strategi prospector merupakan salah satu tipe strategi bisnis yang lebih berfokus pada inovasi produk baru, mengejar pertumbuhan pasar, dan menekankan persaingannya melalui penawaran produk yang unik, sehingga dengan adanya perusahaan yang menerapkan strategi bisnis prospector lebih dihadapkan dengan ketidakpastian risiko yang lebih tinggi.

Hipotesis satu (b) menyatakan bahwa strategi bisnis defender berpengaruh terhadap risiko crash harga saham. Hasil pengujian ini menunjukkan bahwa hipotesis (b) ditolak. Penelitian ini mencoba untuk meneliti apakah strategi defender memiliki pengaruh yang sama dengan strategi prospector. Berdasarkan hasil pengujian yang telah dilakukan, menunjukkan bahwa strategi defender tidak memiliki pengaruh yang signifikan terhadap risiko crash harga saham. Hal ini dikarenakan adanya fokus strategi defender pada stabilitas pasar dan memperhatikan stabilitas jangka panjang yang membatasi jenis produk yang dikeluarkan oleh perusahaan, sehingga kemungkinan terjadinya risiko crash harga saham dalam tipe strategi ini sangat kecil terjadi.

Hipotesis dua menyatakan bahwa persaingan pasar ekuitas berpengaruh terhadap risiko crash harga saham. Hasil pengujian ini menunjukkan bahwa hipotesis dua diterima. Hasil penelitian ini mendukung penelitian terdahulu yang dilakukan oleh Vorst (2016), Chen et.al (2001) yang menunjukkan bahwa persaingan pasar ekuitas cenderung dapat mengurangi terjadinya risiko crash harga saham.

Persaingan pasar ekuitas yang kuat dapat meningkatkan tingkat di mana informasi pribadi tercermin dalam harga saham sehingga dapat mengurangi 
kemampuan manajer untuk menyembunyikan berita buruk, sehingga tidak terjadi kemungkinan penurunan harga saham yang lebih rendah. Sejalan dengan penelitian Chen et al. (2001) peneliti menemukan bahwa kenaikan penerimaan penjualan saham, secara positif memprediksi risiko crash dan kemunduran return negatif.

Hipotesis ketiga menyatakan bahwa strategi bisnis prospector berpengaruh terhadap risiko crash harga saham melalui overvalued equity. Hasil pengujian ini menunjukkan bahwa hipotesis ketiga diterima. Hasil penelitian ini mendukung penelitian terdahulu yang dilakukan oleh Habib dan Mostafa (2017), yang menunjukkan bahwa strategi bisnis prospector berpengaruh terhadap risiko crash harga saham melalui overvalued equity baik dengan menggunakan pengukuran $\mathrm{PB}$ dan PE.

Pengaruh overvalued equity terhadap risiko crash harga saham berkaitan dengan teori yanng dikemukakan oleh Jensen (2005) yang berpendapat bahwa manajer memiliki insentif untuk memperpanjang missevaluation melalui manipulasi laba. Overvalued equity meningkatkan harapan investor tentang masa depan perusahaan. Overvalued equity mengarah pada pengelolaan oportunistik laba yang dapat menghancurkan nilai dan laporan keuangan buram yang dapat merusak kemampuan pasar modal untuk memasukkan informasi spesifik perusahaan secara bertahap ke dalam harga saham. Strategi bisnis prospector lebih cenderung terhadap overvalued equity karena adanya ekspektasi optimis investor tentang prospek pertumbuhan saham yang pada akhirnya dapat menyebabkan crash harga saham (Lakonishok et al, 1994).

\section{SIMPULAN}

Hasil penelitian ini memberikan bukti empiris bahwa strategi bisnis prospector merupakan salah satu faktor yang dapat meningkatkan risiko crash harga saham, sedangkan strategi defender tidak mampu membuktikan bahwa strategi defender berpengaruh terhadap risiko crash harga saham. Hasil penelitian ini juga memberikan bukti bahwa risiko crash harga saham sapat diminima lisir dengan adanya persaingan pasar ekuitas.

Hasil penelitian ini mampu memperkuat teori bad news hoarding theory mengenai penimbunan berita buruk dapat diminimalisir dengan adanya aktifitas investor dalam menemukan informasi yang terjadi sehingga dapat mengurangi asimetri informasi antara pihak investor dan pihak perusahaan. Hasil penelitian yang terakhir yaitu memberikan bukti bahwa strategi bisnis prospector memiliki pengaruh terhadap risiko crash harga saham melalui overvalued equities. Hasil penelitian ini menunjukkan bahwa perusahaan yang menerapkan strategi bisnis prospector rentan terhadap risiko crash harga saham. Penelitian ini juga menemukan bahwa perusahaan yang menerapkan strategi bisnis prospector lebih cenderung terhadap overvalued equity yang dapat menyebabkan risiko crash hargsa saham di masa depan.

Keterbatasan penelitian ini diantaranya yaitu: adanya hasil $\mathrm{R}^{2}$ yang sangat rendah yang menunjukkan bahwa masih terdapat variabel lain yang memiliki hubungan antar variabel yang lebih tinggi, terbatasnya pada pengukuran risiko crash harga saham yang hanya mempertimbangkan skewness negatif, masih sangat sulitnya untuk menemukan data investor dalam pasar modal, dan sampel yang terbentuk relatif sedikit yang termasuk dalam pengukuran strategi bisnis berdasarkan penelitian Habib dan Mostafa (2017) sehingga, pengukuran strategi bisnis dalam penelitian ini menggunakan pengkuran yang sering dirujuk dalam penelitian di Indonesia yaitu penelitian yang dilakukan oleh Habbe dan Hartono (2001). 
Pengaruh

Strategi

Bisnis...

974

Saran untuk peneliti selanjutnya agar mempertimbangkan pengukuran risiko crash harga saham seperti down up volatility (DUVOL). Selain itu peneliti selanjutnya agar mempertimbangkan sampel yang lebih luas yaitu perusahaan publik yang terdaftar di BEI.

\section{DAFTAR PUSTAKA}

Ahsan \& Mostafa, M.H. (2017). Business Strategy, Overvalued Equities, and Stock Price Crash Risk. Research in International Business and Finance 39 (2017) 389-405

Aman, H. (2013). An Analysis of the Impact of Media Coverage on Stock Price Crashes and Jumps: Evidence from Japan. Pacific-Basic Finance Journal 24 (2013) 22-38.

Armstrong, C. S., J. E. Core, D. J. Taylor, and R. E. Verrecchia. 2011. When Does Information Asymmetry Affect the Cost of Capital? Journal of Accounting Research 49 (1):1-40.

Bentley, K.A., Newton, N.J., Thompson, A.M., (2015). Business Strategy and Internal Control over Financial Reporting. Working Paper. University of NewSouth Wales.

Bentley, K.A., Omer, T.C., Sharp, N.Y., (2013). Business Strategy, Financial Reporting Irregularities, and audit effort. Contemporary Accounting. Research. 30 (2), 780-817.

Chen, J., Hong, H., and Stein, J. C. (1999). Forecasting Crashes: Trading Volume, Past Returns, and Conditional Skewness in Stock Prices. Journal of Financial Economic Vol 61, Issue 3, pp 345 -381.

Chi, J, D., and Gupta, M. (2009). Overvaluation and Earnings Management. Journal of Banking \& Finance 33 (9): 1652-1663.

Habbe, A., dan Hartono. (2001). Pengaruh Indikator Makro Ekonomi terhadap Harga Saham. Jurnal Mahasiswa Universitas Hasanuddin Makassar.

Hambrick, D.C. (1983). Some Tests of the Effectiveness and Functional Attributes of Miles and Snow's strategic types. The Academy Managemrnt of Journal. 26 (1), 5-26.

Higgins, D., Omer, T.C., Phillips, J.D. (2015). The Influence of a Firm's Business Strategy on its Tax Aggressiveness. Contemp. Account. Res. 32 (2), 674-702.

Hutton, A.P., Marcus, A.J., Tehranian, H. (2009). Opaque Financial Reports, R2, and Crash Risk. Journal of Financial Economics 94, 67 - 86

Jensen, M. (2005). Agency Costs of Overvalued Equity. Financial Management 34: 5-19.

Jensen, M. C and Meckling, W.H. (1976). Theory of the Firm: Managerial Behavior,

Agency Costs and Ownership Structure. Journal of Financial Economics.

Jin, L., Myers, S. C. (2006). R2 around the World: New Theory and New Tests. Journal of Financial Economics 79, 257-92.

Kim, J. B., and Zhang, L. (2012). Accounting Conservatism and Stock Price Crash Risk: Firm-level Evidence. Hong Kong: City University of Hong Kong.

Kim, J.B., Li, Y., Zhang, L. (2011a). Corporate Tax Avoidance and Stock Price Crash Risk: Firm-level analysis. Journal of Financial Economics 100, 639-662

Kim, J.B., Li, Y., Zhang, L. (2011b). CEO versus CFO: Equity Incentives and Crashes. Journal of Financial Economics 101, 713-730.

Lakonishok, J., Shleifer, A., and Vishny, R.W., (1994). Contrarian investment, extrapolation, and risk. Journal of Finance 49 (5): 1541-1578. 
Li, Xi., Steven, S.W., Xue, W. (2016). Trust and Stock Price Crash Risk: Evidence from China. Journal of Banking and Finance, $1-54$

Miles, R.E., Snow, C.C., Meyer, A, d., and Coleman, H, J. (1978). Organizational Strategy, Structure, and Process. Stanford University Press, Stanford.

Rajagopalan, N. (1997). Strategic Orientations, Incentive Plan Adoptions, and Firm Performance: Evidence from Electric Utility Firms. Strategy Management Journal 18(10), 761-785.

Vorst, Patrick. (2016). Equity Market Competition and Stock Price Crash Risk. papers.ssrn. School of Business and Economics Department of Accounting and Information Manageme 
